\title{
Understanding the Dynamics of Engaging Interaction in Public Spaces
}

\author{
Peter Dalsgaard, Christian Dindler, and Kim Halskov \\ CAVI \& Centre for Digital Urban Living \\ Aarhus University \\ Aarhus, Denmark \\ \{dalsgaard, dindler, halskov\}@cavi.dk
}

\begin{abstract}
We present an analysis of three interactive installations in public spaces, in terms of their support of engagement as an evolving process. In particular, we focus on how engagement unfolds as a dynamic process that may be understood in terms of evolving relations between cultural, physical, content-related, and social elements of interactive environments. These elements are explored through the literature on engagement with interaction design, and it is argued that, although valuable contributions have been made towards understanding engagement with interactive environments, the ways in which engagement unfolds as a dynamic process remains relatively unexplored. We propose that we may understand engagement as a product of the four above-mentioned elements, and in our analysis we provide concrete examples of how engagement plays out in practice by analyzing the emergence, transformation and relations between these elements.
\end{abstract}

Keywords: Urban computing, engagement, interaction design.

\section{Introduction}

For a number of years, we have each explored the notion of engagement through a series of design experiments. This has led to ongoing discussions, both among ourselves and with our peers, regarding the nature of engagement, and the ways in which it unfolds when people encounter interactive systems and installations.

The notion of 'engagement' is so broad and encompassing that we find it most productive to consider engagement as a perspective on interaction, rather than a clearly defined entity. This perspective on engagement focuses our attention on how people, as resourceful individuals and groups, invest their time, skill, knowledge, and imagination in interactive environments. As argued by Rogers [30], it prompts us to consider how people proactively use their capacities through technology, and how technology supports the use and extension of skills. By identifying engagement as a perspective on interaction, we position it at the same level of abstraction as notions such as 'usability', 'embodiment' [8], and 'affect' [12], as perspectives on interaction. These perspectives have a dual nature: on the one hand, they may serve as analytical means for focusing the studies of interactive systems; on the other hand, the perspectives that influence designers may have concrete consequences for the design of new systems. 
Turning to the literature on interaction design, the issue of engagement has been dealt with from a range of positions, from programmatic accounts arguing that engagement may be the centre of research agendas (e.g. [30]) to more detailed studies exploring particular design strategies for sparking engagement ([14], [4]), or concepts for understanding how particular attributes support engagement (e.g. [10]). While it has proved productive to study engagement with particular technologies, these technologies do not exist by themselves. Rather, they are parts of larger assemblies [19], wherein various technologies, physical properties, and forms of cultural practice shape people's engagement with them. From our perspective, a focus on the individual object is thus too narrow for understanding people's engagement with technology; an account is needed, that is capable of capturing engagement as a product of relations between physical, cultural, social, and content-related elements. Moreover, while studies in interaction design have succeeded in identifying specific aspects of engagement, we see a need for studying the dynamics of engagement, as it unfolds in concrete situations, and with assemblies of technologies. To pursue this line of inquiry, our paper is structured around two concerns; first, we provide an account of engaging interaction, keeping our focus on how engagement evolves, not only as a relationship between people and single technologies, but in complex situations involving other people, cultural practices, content, and physical surroundings. Second, building on this account, we explore in more detail the dynamics of engagement as it unfolds in concrete situations.

To explore these dynamics, we have brought together three cases from our work. Our first case, Aarhus by Light, was a large-scale, urban installation of an interactive media façade in a public space, whereas the other two cases took place in different settings. Our second case, the Hydroscopes, was an interactive installation exploring new potential for engaging experiences at museums and science centres. Third and last, the LEGO Table was an interactive installation that explored new potential for digital marketing at a department store. From an analysis of these three cases in conjunction with one another, we have found that engagement with interactive installations may be construed as a highly relational phenomenon, characterized by the interplay between physical and spatial conditions, socio-cultural practices and constructs, and the content of the installations. In this paper, we focus on the dynamics between these four properties, and we will particularly focus on the transformations that occur during interaction, both between these aspects (for instance, transformations that concern both social and physical aspects) and within them (for instance, transformations of social aspects). Through the analysis of two specific instances from each of the three cases, we explore how engaging interaction may be understood as a relational, dynamic, and transformative phenomenon involving the above-mentioned four aspects as crucial elements.

Before we turn to the specific analyses, we first introduce the four elements of engagement.

\section{Elements of Engagement}

Based on a study of the research literature, we have identified four elements of engaging experiences: cultural practices, physical conditions, the content of the installations, and social practices. In this section, we introduce these four elements, and address how they are important aspects of engaging experiences. 


\subsection{Cultural}

By highlighting the cultural element of interaction, we wish to bring attention to how cultural aspects come to bear on engagement. The use of interactive technologies typically unfolds at institutions or in situations that embody particular forms of practice. In a sense, these embody expectations concerning the kinds of activities and actions that may take occur, which in turn shape the perception of, and engagement with interactive technologies. Cultural conventions and norms may both relate to particular forms of social interaction, or particular ways of using the physical environment. Whether going to a concert, visiting a museum, or walking through the city, particular practices and conventions unfold, and are more or less implicitly expected of people. People may follow these conventions to greater or lesser extents. De Certeau's [6] description of 'walking in the city' eloquently illustrates how people are influenced by the rules of power and culture determining spatial practices of moving through urban landscapes, but also the particular ways in which people circumvent and bend rules. Particular cultural conventions may be learned and shared among people, or may be manifest in artefacts and surroundings that are crystallizations of particular practices. Cultural historical activity theory ([18], [26]) explores the concepts of 'institution' and institutional forms of practice in great detail, highlighting how various institutional settings promote particular activities, and how artefacts reflect cultural practices. Our understanding of how socio-cultural codes of behaviour affect public interaction with digital installations is further informed by the notion of performing perception [5]. This refers to the phenomenon that most people experience, of being consciously or unconsciously aware of the constant possibility of being observed, and adjusting their behaviour accordingly, which will usually affect how an installation will be used in practice.

Often, designers take advantage of established forms of practice to improve the usability and usefulness of their products. In some situations, designers will deliberately adopt a strategy of breaking with convention, in order to spark reflection (e.g. [9]), or as part of research efforts to understand these practices, as in the use of breaching experiments [13] or provotypes [25].

\subsection{Physical}

Physical presence and actions are central to many, if not all, engaging experiences. Physical engagement may take a number of forms. In a straightforward sense, physical engagement covers the physical manipulations carried out when controlling input devices and handling tangible user interfaces, and the bodily movements that control playful, movement-based systems such as the Wii, for instance. This understanding of physical engagement is thoroughly documented in the literature (see [22] for overview). However, our definition of physical engagement is expansive, and also covers aspects of embodiment, affect, interactive cognition, and intertwined action-reflection. As argued by Dourish [8], embodiment, 'the property of being manifest in and as a part of the world', has become a central feature of many recent theoretical developments in HCI. Our existence in the world as physical beings is central to the ways in which we make sense of the world, and this basic premise is inescapable, when we examine how people's engagement with technology unfolds in 
practice. Our physical presence in a given setting means that we are affected by our surroundings even before we consciously enter into sense-making processes, which is the basis for Fritsch's work on affective engagement in interaction design [12]. Furthermore, several strands of research have addressed the notion of sense-making through physical action: when we make sense of things, reflect upon, analyse, and make plans for our actions in the world, these processes are often supported by physical actions or manipulations, as explored in the fields of distributed cognition [20] and interactive cognition [15], for example. These schools of thought also stress the importance of understanding the role of physical materials in our interaction with our surrounding environment. In the field of interaction design, the intertwined nature of action $<>$ reflection and mental $<>$ physical has been explored from a number of angles, for instance, through the externalization and internalization of culturalhistorical activity [26], through the exploration of aesthetic interaction [29], and the means of engagement in interaction design [4] based on pragmatist philosophy.

\subsection{Content}

When we interact with digital systems, or with other types of media, for that matter, there are various ways of engaging with the content of the medium or system. Our understanding of engagement with content is influenced by Dewey's pragmatist aesthetics [7], in that we consider engagement to occur when a person invests part of herself in the encounter with the content. It is not inherent in the content itself, although the content may be structured in ways that make certain encounters and experiences more likely.

Engagement with content may take place both with regard to specific parts of the content, such as a discrete instance in a narrative, or as a response to the composition of longer passages of the content, or even the totality of the content. Often, an analysis of engagement with content must be longitudinal, and encompass the entire encounter, since some of the content may initially seem insignificant or troublesome, but may later gain new significance as more content is explored or presented.

Much content comprises recognizable structures and elements, such as genres, archetypes, or narrative structures [16]. However, engagement is often sparked by elements of conflict that prompt an inquisitive attitude [3]. Crafting engaging content is, therefore, also a question of addressing the balance and tension between recognizable and perplexing elements.

Often, when content is static or linear, engagement with it may occur as an internal process, although the nature of the subject of our research, interactive systems, frequently demands some form of overt action. This is particularly prominent in those cases in which the content is dynamic and has a non-linear structure that prompts interaction, for example, hypertext systems, responsive installations, interactive games, and so forth ([1], [23]).

\subsection{Social}

With regard to the social element of engaging interaction, we focus on the relation between users/potential users of the interactive installation. Our exploration of social aspects of engagement is inspired by contributions concerning computer supported cooperative work [17], which addressing the relationships between users and systems 
in general, and more specific contributions concerning aspects such as social interaction [28] and co-experience [11. In order to address engaging interaction, we have identified the following social relationships as crucial for understanding the various forms of engaging interaction. Social Interaction describes situations in which two or more people with no prior relationship interact, in contrast to Group Interaction, which refers to interactions initiated by two or more persons who approach the table as a group, for instance two friends, or a parent and his child. Individual Interaction describes interactions carried out by a single person. One particular kind of interaction is self-expression, wherein one or several individuals interact with an installation, with a particular focus on having others watch them [5].

Moreover, we distinguish between various forms of initiating and resuming engaging interaction (see [27]). We use the term Watch-and-join to refer to interactions initiated by people who watch the installation, then join those who are already interacting with it, in contrast to Watch-and-take-over, which describes situations in which people watch the installation, and wait until other users have left, before engaging in the interaction. Though not in itself a social element, we also distinguish between Walk-up-and-use, which applies when a person approaches the installation and immediately begins interacting with it, and Interact-and-run, in which case a person only briefly initiates the interaction before leaving the installation. Return describes the behaviour of people who return to the installation after interacting with it previously.

\section{Analysis}

In the following, we use the above four aspects and their associated sets of distinctions as a platform for analyzing two specific vignettes from each of the four cases. In each of the cases, we have carried out extensive studies and analyses of user interaction in order get a better understanding of engaging interaction. The vignettes presented here have been selected on the basis of said studies and analyses because they are representative of the types of interaction that occurred with the installations in question, and because they embody the dynamics of engagement in a way that can be conveyed in a relatively straightforward manner.

The sections are structured such that we first present the case and our approach to studying it; we then present two vignettes for each case in which different aspects of engagement come into play. In our presentation and analysis of the vignettes, we will focus in particular on three ways in which the dynamics of engagement unfolds: how engagement emergence as an encounter between a person and an installation in situe; how engagement concerns relations between one aspect and another aspects, for instance how social interaction in a situation is scaffolded by content; and how engagement unfolds as a series of transformations, for instance when individual engagement is transformed to social engagement, or when an embodied, individual state of engagement is suddenly transformed because cultural aspects come into play.

\subsection{Aarhus by Light}

Aarhus by Light was a two-month experiment with an interactive media façade at the Aarhus City Concert Hall (Musikhuset) in Aarhus, Denmark. The main component of 
the installation was an interactive media façade designed to explore how digital technologies can affect and transform public behaviour and social interactions. It was developed by a research group at the Digital Urban Living research centre, in order to explore new possibilities of digital media in urban settings. The installation was designed for the large glass façade of the concert hall building, which was fitted with 180 square metres of semi-transparent LED screens. The LED screens were distributed in a irregular array behind the surface of Musikhuset, which faces a public park (Fig. 1).
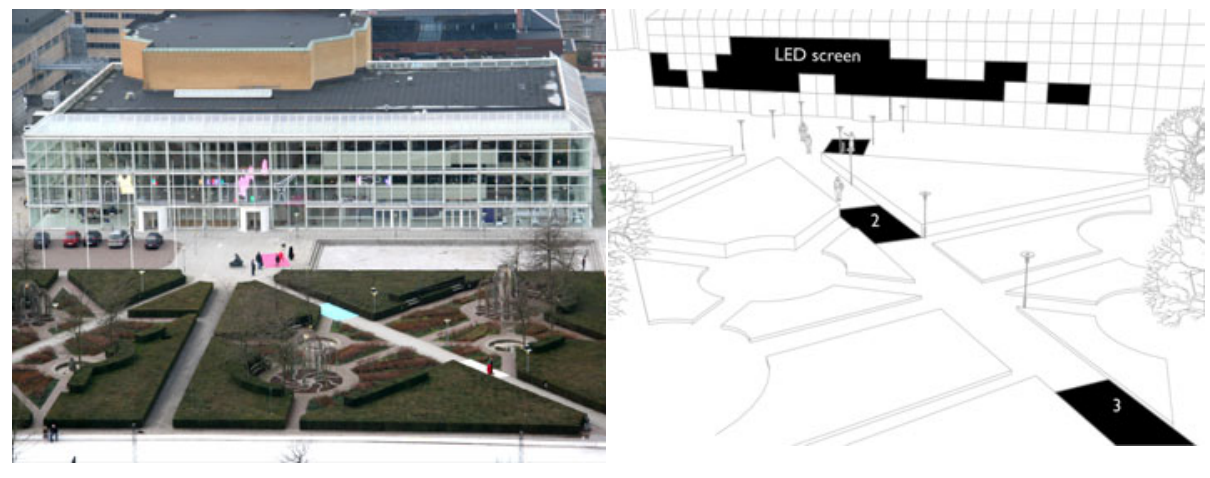

Fig. 1. Musikhuset with the media facade installation and the three interaction zones

Visitors to the park were greeted by a spectacular view of animated creatures crawling around the structure of the glass façade, along with a constantly moving outline of the Aarhus skyline. When visitors walked through the park, they passed through three interaction zones marked by coloured carpets (pink, blue, and yellow). Using these zones allowed visitors to enter the world of the small, luminous creatures. The luminous creatures were social beings that were always (or usually) happy to see you. In the interaction zones, camera tracking translated the visitors' presence and movements into digital silhouettes on the façade, and through the silhouettes, visitors could caress, push, lift, and move the small creatures. The creatures would wave back, fight, sleep, climb, jump, kiss, and occasionally, leave and return, thereby establishing a relationship with the visitor that was not only physical and embodied, but also emotional and narrative.

Our research methodology for studying Aarhus by Light consisted of collecting empirical data in a number of ways: we compiled system data logs of the number and duration of registered interactions; we carried out a number of in-situ observations during the two-month period; we conducted twenty-five structured interviews with users; we video-recorded approximately one hundred interactions with the installation; and finally, we made time-lapse videos compiled from photos taken from a nearby tower, both during and after the two-month period, in order to observe largescale interaction patterns. In our subsequent analysis, we have combined these sources of data in order to obtain a richer understanding of how people engaged with the installation. Since the installation was placed in a prominent urban space, and was in 
use for a long period, it provided us with the opportunity to explore patterns of interaction that extended beyond the individual encounter.

In the following presentation and analysis of how people engaged with the Aarhus by Light installation, we present two vignettes that were typical of the use patterns we observed. It is evident that physical, cultural, social, and content-oriented aspects are intertwined in these cases. In the first of the two representative vignettes, it seems that physico-spatial and content-oriented aspects are the most prominent concerns. In the second vignette, cultural and social aspects are the focus.

\section{Physical Space and Social Relations}

A family, consisting of a father, mother, daughter, and son, enters Musikhuset's park from the main street. They walk down the path in which the interaction zones are located. The children start making gestures in the first zone they reach, indicating that they have noticed the interactive façade elements, and the connection between the interaction zones and the silhouettes on the façade. When they reach the interaction zone delineated by the carpet closest to the façade, the boy and girl move about and gesture, while keeping their eyes on the display. The parents do not interact, but walk slowly around in the vicinity of the interaction zones. The boy goes through a range of motions - jumping, spreading his arms and imitating a bird, waving, and trying out strange walks. When he is most active, the girl steps off the carpet. At one point, the boy takes off his jacket and waves it about, seemingly pleased with the effect it has on his silhouette and the creatures on the façade. The girl is less active, but also tries out different moves while watching the response on the façade. They occasionally turn around to look for their parents, who are also in the park, but most of the time their attention is directed at the façade.

While the brother and sister are playing there, a mother and her daughter approach the carpet. The mother instructs her daughter to enter the carpet that marks the zone. The daughter waves her arms and wiggles briefly then looks towards her mother, who nods, and they leave. A group of children arrives. The boy and girl look at the group, and move to the edge of the carpet, remaining in the interaction zone. The new group of children waves and shouts while passing through. A girl from the group remains on the carpet. She moves, jumps, and so on. The boy and girl who were originally on the carpet step off it, leaving it to the newly arrived girl. The boy watches the new girl and her silhouette for a while, then moves onto the carpet and makes a few gestures, but in a more subtle way than before.

If we focus on the recurring actors in the vignette, the brother and sister, it is clear that their engagement unfolds as a series of interconnected events - or a trajectory, in the words of Benford et al. [2]- as they move through the park in front of the Musikhuset, and explore the features of the installation. In at least three ways, the physico-spatial aspects seem very important to understanding their engagement: first, with regard to their physical movement through the park, among the interaction zones; second, with regard to their embodied, playful exploration of the installation; third, with regard to territorial aspects.

Concerning the first issue, the installation encompasses not only the façade, but reaches into the park, and is visually very prominent, especially at night. Looking at the family in the vignette, there is a flow between the different interaction zones as they approach the concert hall, and the interaction with the luminous creatures 
becomes increasingly evident. The design of the installation allows for engagement to emerge in different ways, and for users to shift between different modes of engagement. It also allows for a social appreciation of the installation, since the individual's interactions are made visible and enhanced through the silhouettes on the façade. This leads us to the second concern, the embodied and playful exploration of the installation. We can clearly see the emergence of physical engagement as the children enter the different interaction zones, culminating in the zone nearest the building. The boy, in particular, seems very engaged in exploring and experimenting with all kinds of movements and gestures and his engagement is transformed from an initial curiosity to a very active state. The girl is a bit more hesitant, but also tries out a variety of moves; her engagement also undergoes transformations, often towards a more observant state, because of her brother's activity. Throughout this period of gesturing, they are both very attentive to the façade, and there is a clear relation between the physical and content-oriented aspects of their engagement. Our observations and interviews generally indicate that the most intriguing elements of the content were the luminous creatures that responded to the silhouettes. Concerning the third issue, we see several territorial aspects at work. When the brother and sister are on the carpet, they move about freely. Then, as groups pass through, they make way, although they keep their attention on the façade. Finally, when the new girl arrives, the boy pays attention to her, and moves to the edge of the carpet, making way for her. During this passage, his gaze wanders from the girl to the façade, and back. He is clearly engaged with not just interacting himself, but also with the social relation brought about by the installation.

These territorial issues may be understood as a combination of physical and social aspects of engagement. There seems to be an implicit understanding of sharing the space, first between the brother and sister, then, as they move aside for the larger group, while keeping their focus on the façade; the final episode involving the new girl is a bit different, for the boy seems just as interested in observing the girl, and his movements now implicitly signal to her that he recognizes her presence and wants to share the space. Another interesting episode that highlights the role of social aspects is that of the girl who is brought to the carpet by her mother. In our reading, one of the main reasons the girl interacts with the installation seems to be that the mother prompts her to do so. This girl seems equally preoccupied with satisfying her mother and interacting with the content through physical movements.

\section{Cultural and Social Aspects}

A woman moves back and forth across the carpet while watching the screen. A few metres away, two men watch the screen. One of the men glances at the woman occasionally, but then turns his eye to the façade again. The woman walks away, and the man slowly approaches the carpet. He puts his hands in his pockets and turns his side to the façade. He smiles at the other man, and walks casually across the carpet, seemingly not paying much attention to it. He then walks around the edges of the carpet, making small wiggling motions, while keeping his hands in his pockets. As a couple approaches and passes through the zone, he stands back from the carpet. After they have passed, he once again steps onto the carpet and moves about. His interest shifts between observing his silhouette on the carpet, and observing how other people look at him while he interacts with the installation. 
As was seen in the first vignette, the physico-spatial, social, and content-oriented aspects all come into play, when we consider how the man in this vignette is engaged in the interaction situation. While he is obviously curious, and wishes to explore the content, as we see in his intentional gestures and movements while on the carpet, what is most striking is his attention to the social aspects. He waits some metres away from the carpet while the woman interacts. We can construe this as an emergent social engagement. Then, as she leaves the carpet, he takes his turn and we see the emergence of physical and content-oriented elements that transform his over-all state of engagement, although this is very clearly related to and framed by the social and cultural elements of the situation. The man is curious, but his movements are more subtle than those we observed in the previous vignette, in which the boy's physical exploration was very adventurous and energetic. In this second vignette, the man's behaviour is more akin to how we would typically expect adults to behave. The spatial layout of the environment also comes into effect when the man waits to take his turn, and makes way for others, which communicates a certain social etiquette; on the other hand, it is also apparent in the way in which he seems simultaneously curious enough to explore the content, yet aware that he should behave like an adult, and therefore restrain his movements. In this case, our understanding of engaged interaction with the installation cannot be decoupled from an awareness of the established practices of public behaviour. In this respect, Aarhus by Light highlights the importance of examining both the space in which an installation will be placed, and the shared social practices of that space.

\subsection{Hydroscopes}

Our second case derives from our work in the Interactive Experience Environments (IXP) project, aimed at exploring novel interactive installations for museums and science centres. Specifically, we focus on a prototype designed for the Kattegat Centre, which is a marine centre displaying marine life from all over the world. The centre is primarily composed of large aquaria with glass sides that allow visitors to explore the variety of marine life. As part of our research efforts, we designed a prototype installation for the centre, where visitors were invited to construct fish for a virtual ocean. Fish were constructed using a physical construction kit with embedded
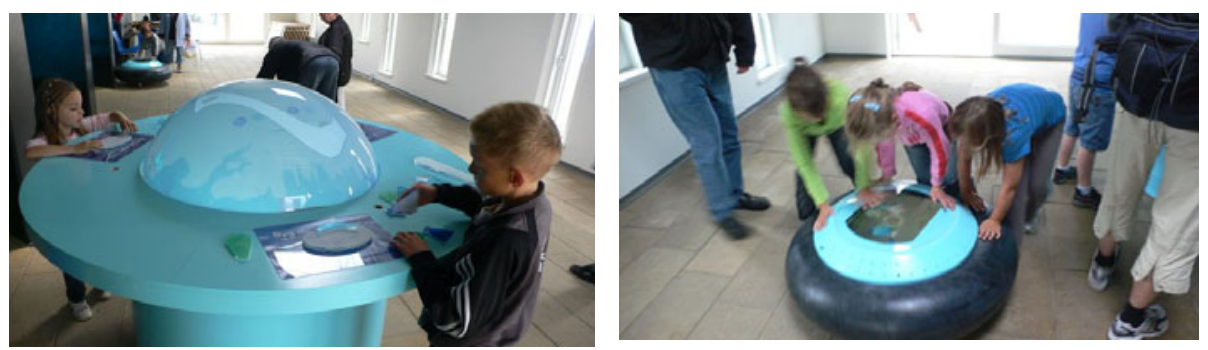

Fig. 2. (A)Visitors constructing fish based on a physical construction kit and (B) exploring the virtual ocean using the Hydroscopes (right) 
RFID chips. The construction kit contained the heads, bodies, fins, and tails of a variety of existing species of fish. From these pieces, visitors could create imaginary fish that combined qualities of existing species (Fig. 2, A). After visitors created the imaginary fish, they where invited to release their fish into a virtual ocean that was inhabited by the fish created by other visitors. The only way to explore this ocean was by using digital Hydroscopes (Fig. 2, B). The hydroscopes provided a view into the virtual ocean, which could be explored by pushing the Hydroscopes along the floor.

The research methodology for the Hydroscopes consisted of in-situ observations over two periods of four days. Observations where supplemented by continuous video recordings of use situations. Furthermore, contextual interviews with visitors where conducted during the evaluation period. Together, these sources of data provided the material form which to gain a nuanced understanding of people's engagement with the installation.

The use of the Hydroscopes at the Kattegat Marine Centre exemplifies the dynamics between several of the elements of engagement introduced in the previous sections. Here, we focus more specifically on two examples that illustrate transformations between individual and social interaction, and between exploration of content and physical engagement.

\section{Individual and Social Interaction}

The Hydroscope installation was placed next to a series of large windows that provide a view into one of the larger aquaria of the marine centre. The three images in Figure 3 are snapshots of a sequence in which a user moves (the girl in the purple sweater) between the Hydroscopes installation and the large windows.
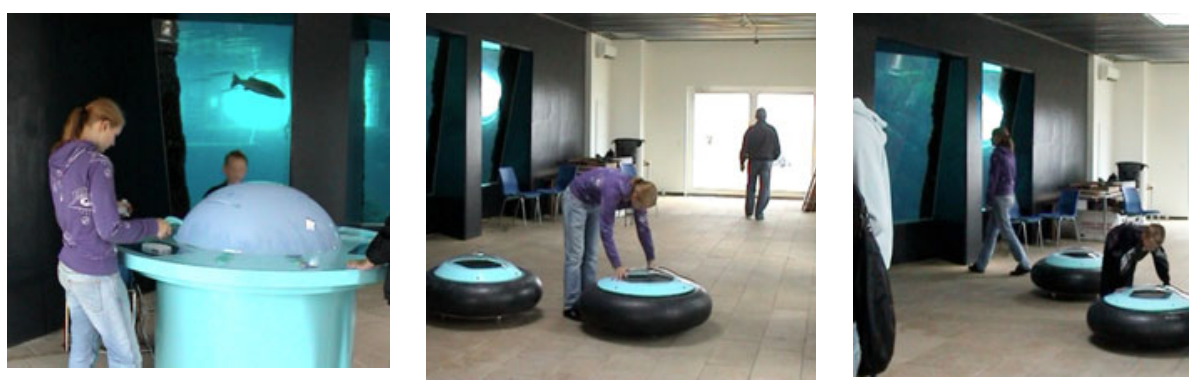

Fig. 3. (A) The girl moving between the construction table, (B) the Hydroscopes and (C) the large aquarium

There are several things worth noting, with regard to the elements of engagement described in the previous section. During the first part of the user's interaction (Fig. 3, A), the girl is using the construction table by herself, and goes back and forth between the Hydroscopes and the construction table every time she has constructed a fish. Finding her own fish in the Hydroscopes inspires her to create new fish, which in turn prompts her to explore the digital ocean through the Hydroscopes. After approximately ten minutes, the girl looses interest in the Hydroscopes, walks to the large window of the aquarium, and spends a few moments looking at the fish (Fig. 3, 
C). After having watched the aquarium for a few moments, the rest of her family enters the room, and her father begins to construct a fish at the construction table. The girl immediately joins her father, and they collaborate on building a new fish. As her father is apparently using the installation for the first time, on several occasions the girl instructs her father on how the installation works (Fig. 4, A). After a few moments, her attention turns to her mother and her younger brother, who are exploring the digital ocean through one of the Hydroscopes. She walks to the Hydroscopes, and spends time moving one of these around with her brother (Fig. 4, $\mathrm{B})$, before returning to the large aquarium windows.
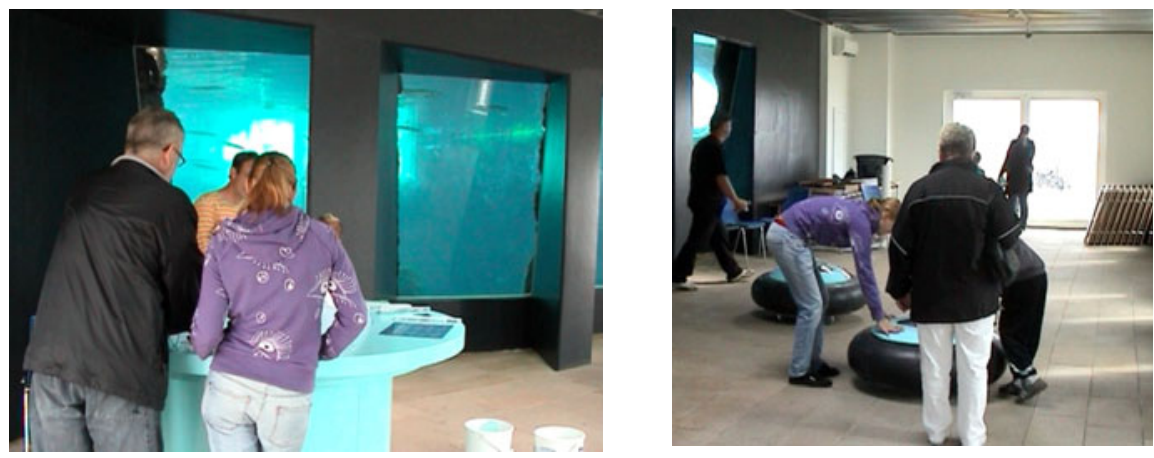

Fig. 4. (A) The girl creating wish with her father and (B) using the Hydroscopes with her brother

This example illustrates how the girl's engagement with the installation goes through a transformation from being individual to being social. In particular, it is worth noting that the girl initially seems to loose interest in the installation, once she has created a few fish, and the installation offers no additional depth or intrigue to keep her engaged. When she returns to the installation, her engagement takes a different form, and is driven by her social interaction with her family. In this example, the transformation from individual to social elements prompts a new mode of engagement, where the relationship between the girl and the installation is transformed.

\section{Content and Physical Interaction}

In the second example, involving the Hydroscopes, we focus on transformations between being primarily engaged with the content, to being engaged with the physical form of the hydroscope.

Figure 5 shows a snapshot from a sequence where a boy is using the hydroscopes to explore various aspects of the digital ocean. The boy is visiting the marine centre with his family, who are also exploring the installations. The interesting aspect of this sequence is how the boy's engagement continuously fluctuates between a relatively calm and concentrated exploration of the digital fish that he can see in the Hydroscopes (Fig. 5, A), and playful activity where the boy attempts to sit on the hydroscope, or use it as a stock car to ram into the other Hydroscopes (Fig. 5, B). 

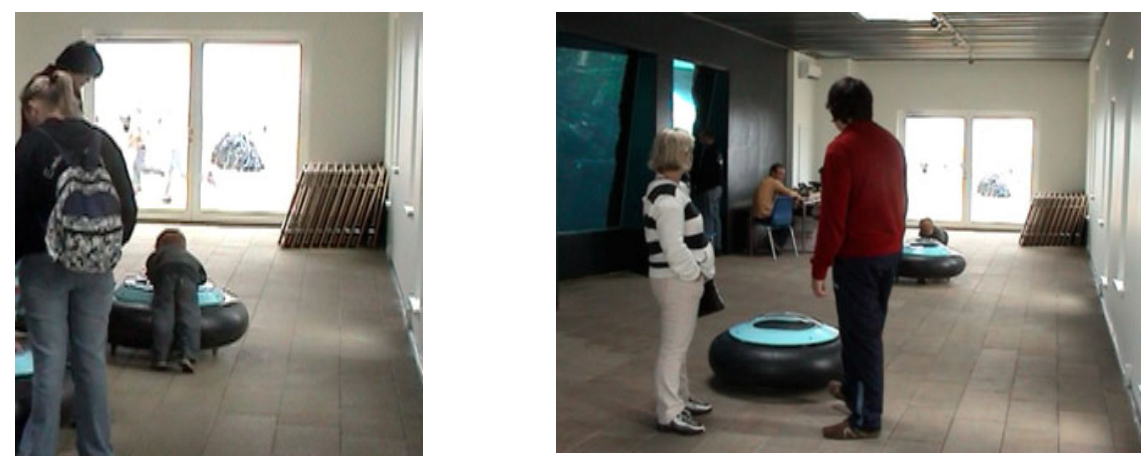

Fig. 5. (A) A boy exploring the content of the Hydroscopes and (B) using the Hydroscope as a stock car (right)

During this sequence, the boy uses the Hydroscopes by himself, and moves them back and forth over the entire floor surface. At several points, he moves the Hydroscopes specifically towards his family members.

The fluctuations between calmly exploring the content of the Hydroscopes, and the more physical and playful activity seem to rely on several elements. The physical design of the hydroscope seems important in this sequence; as the boy attempts to spin the Hydroscopes as fast a he can, he uses them as trolleys, pushing them forward while sitting on them, and he uses them as stock cars, ramming them into each other. However, the boy's playful activities also embody a distinctly social element. During his play, he often looks up to see where the rest of his family is, and moves the Hydroscopes towards them. At several points during the sequence, the boy pauses in his playful activities, and spends a few moments looking more closely at the digital ocean and the fish that have emerged as he has moved the Hydroscopes.

\subsection{LEGO Table}

The LEGO Table is an interactive table, designed to market LEGO Bionicle figures in a retail setting ([27]). The physical design of the LEGO Table comprises an interactive surface, a thirty-five-inch monitor, and four boxes with Bionicle figures (Fig. 6). The content consists of the four Bionicle figures: The two heroes, the large Lewa Nuva, and the smaller Tanma, in green, and the two villains, the large Radiak, and the smaller Antroz, in red. The digital content is a high-quality animation associated with each of the four figures, each of which can stand, walk, hover, fly, and fight. Moreover, Tanma can connect to the back of Lewa Nuva, and Antroz can connect to the back of Radiak. The interaction works in the following way: When a physical Bionicle figure is placed on the table, a corresponding animated figure appears on the display, and as the figure is moved on the table, the digital figures moves (either flying or walking) in the virtual 3D world. If a red and green figure approach one another, they begin fighting. Moreover, figures of the same colour have matching base profiles (Fig. 7, A), and when physically interlocked, the small figure jumps on the back of the big figure, in the virtual world. The interaction is implemented using reacTIVison software [21], together with visual markers on the bases of each of the boxes. 


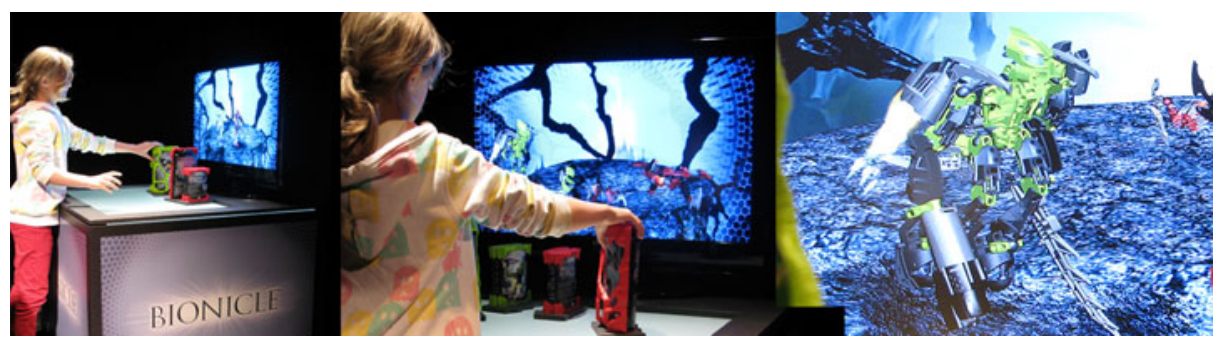

Fig. 6. The LEGO table
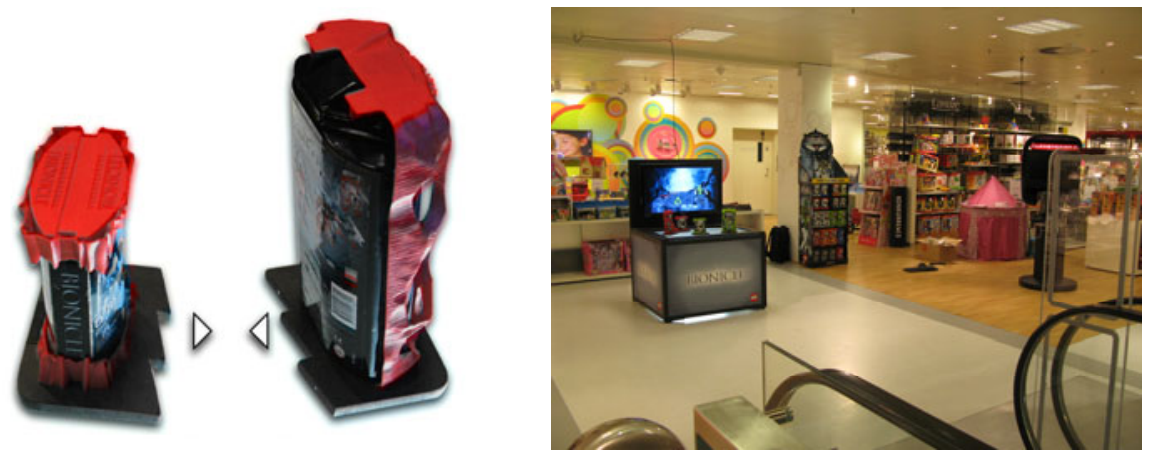

Fig. 7. (A) The matching base profiles (B). The LEGO Table at the department store

The LEGO Table was in operation for a four-week period at a Danish department store. During this period, the interactive table was located in one of the main corridors, and the fact that the table faced the top of the ascending escalator facilitated easy access to the table (Fig. 7, B). During one busy shopping Saturday, activities around the interaction table were video-recorded. The initial analysis reveal that a total of 124 people were observed interacting with the table and in the six hours of observation data form the use of the LEGO table we identified 94 interactions ranging from six seconds to 25 minutes in length, see [27]. An analysis of the distribution of gender and age shows that a wide variety of people engaged in the interaction, though most were boys less than 16 years of age. The following two situations are from that particular day. The first situation represents a dynamic instance of engaging interaction including aspects of physical tangibility and social relations, whereas the second situation revolves around dynamic aspects of physicality and content.

\section{Physical Tangibility and Social Relations}

In one observed instance, two girls approach the LEGO Table, and one of them raises the large red box while watching the virtual world, then interacts with the two red figures in an exploratory, unstructured way, trying to make sense of the installation and of what she can do with it. The emergence of engaged interaction is enabled by the physicality of table, tangibility of boxes, and the content of the installation in terms of the familiar Bionicle universe. Once she starts using the table, she shifts smoothly from being a regular visitor to the store, to a mode in which she plays with 
the figures. Initially, she interacts individually, while the second girl watches the interaction, but in few moments she too joins in, and starts exploring the two green figures on her own. Briefly, the girls move the figures about the table in an unstructured manner, and soon, acting together, begin banging them together playfully, watching the display to see what happens. We can observe a social transition from individually exploring the LEGO table to playing together enabled by the two sets of physical boxes and but also by content (Bionicle figures do fight). A moment later the first girl disengages (i.e. leaves), and the other girl remains at the table, investigating its functionality, and various ways of banging the figures together. A boy walks up to the table and starts watching the girl, as does another girl, but their mother comes to pick them up, without their having directly interacted with the table. The second girl manipulates the figures in various ways, at certain times so quickly that they are not fighting in the virtual world. At one point, she arranges the figures systematically on the table and leaves, but approximately two minutes later, the second girl returns to the table, and resumes her individual interaction.

To summarize, Engagement and transformation of social relations are enabled by both content and physicality. Initially, the first girl is concerned with the content of the installation, in terms of both the physical boxes and the virtual figures. She immediately grabs the boxes, and starts exploring what she can do with them. Enabled by the physicality of the boxes and shared display, the two girls jointly inquire into the nature of the installation, explore what they can do, and the effects of their actions. The two sets of physical boxes enable the girls to explore the installation, both individually and together.

We can observe several forms of social engagement. The first girl starts out on an individual basis, while the second girl watches her, but the second girl joins in, and begins exploring the installation in parallel with the first girl; however, in a few seconds, she switches to interacting with the other girl, by physically banging the boxes together. We also see how the first girl smoothly moves in and out of the situation, as well as the instance in which two other children are briefly spectators of the situation, without being directly engaged in the manipulation of the boxes.

\section{Physicality and Content}

In a direct continuation of the situation discussed above, the second girl starts lifting the figures, playfully exploring the packages of the large red and green figures. She then raises all four figures off the table, while looking for, and calling to her friend, the first girl. The second girl carefully places each figure on the table horizontally, red figures on the right, green figures on the left. The first girl returns to the table and joins her friend, leaning on the table, beginning to explore the packages, and moving the two red figures about. As one more instance of transition from individual to social engagement the two girls enters the figures in combat, moving them quickly against one another. The second girl moves, and quickly lifts the figures, before replacing them on the table. The first girl couples and decouples the red figures, and inspects the package, and bottom of the large figure. The two girls engaging the figures in combat while turning them around and lifting them. The first girl moves to the left of the table, and moves the figures from there, before moving back to the front of the table. The second girl bangs the two small figures together, while the first girl watches passively for ten seconds. The large green and red figures are left untouched. 
The two girls couple the figures; the first girl moves the red figures, the second the green figures. The second girl decouples the green figures, and tries to couple the small red and small green figure. Next, the girls couple their figures as they had previously. They start to choreograph the figures' movements in various ways, then suddenly decouple them, and start banging the small figures together. The figures in the virtual world float in the foreground, and do not fight. The girls' attention continuously shifts between the physical figures and the display. They resume the combat on the table, moving all the figures around. The second girl lifts the small green figure, and opens its lid. She abruptly removes both the green figures from the table. The first girl follows suit, and removes the red figures, while touching the table with her hand. The second girl also touches the table with her hand. The interaction lasts for about two and a half minutes ${ }^{1}$.

The interaction described above is a complex, dynamic flow of transformations between engagement with physical objects (both the boxes and the table), and play with the boxes. The embodied interaction is enabled by the physicality of the boxes: we can observe moments when one of the girls manipulates a single box, and others when, on her own, she bangs two boxes together, as well as instances when the two girls fight, using the boxes. Sometimes, they seem to focus on the physical boxes, rather than the relationship between the physical boxes and the virtual content. The process moves in and out of modes in which the girls seem to be either playing with the boxes, owing to the well-known and easily recognizable Bionicle figures, and modes where they seem, if not puzzled by the installation, then at least trying to determine how it works, for instance, by seeing what happens when they couple and decouple a small and a large figure. Eventually, they shift from focusing on the figures, to inspecting the table itself.

\section{Discussion}

Our analysis of selected instances and situations of the three cases presented has provided insight into the nature of the dynamics of engaging interaction, in particular, how engagement unfolds as developments in the relationships between the physical, social, cultural, and content-related aspects. In our analyses of the cases, we have employed the concepts of emergence, transformations and relations in order to describe the dynamics of engagement. We have done so to explain how engagement first occurs, how it unfolds and changes over the course of time, and how different elements are connected and affect each other in this process.

Comparing the three cases, they all illustrate how individual elements may at times play particularly prominent roles. Looking first at the physical and spatial aspects, the physical movements through the park of Aarhus by Light, and the location of the LEGO Table were essential to the emergence of engaging situations. In all three cases, we observed embodied, playful exploration of the installations.

Our observations and interviews also show that content plays a role, even when it is not particularly complex. In the case of the LEGO Table, the familiar Bionicle Universe, with its easily recognizable cast of figures, provides an entry point,

\footnotetext{
1 This paragraph is an excerpt from [27].
} 
enabling children to engage with the installation. In contrast, Aarhus by Light seemed to attract people with the unfamiliarity of the installation. Our example of the use of the Hydroscopes shows how the content, in terms of creating and exploring various kinds of fish, was capable of engaging visitors, but that often, as in our example, transformations occurred where visitors shifted their focus to the physical aspects, or engaged in social activities around the installations.

The social dynamics were prominent in all our cases, and it was particularly striking to see how fluidly people moved in and out of various social constellations. The social dynamics seemed to be facilitated by the physical elements for instance, the two sets of Bionicle figures, or the open interaction space in front of Musikhuset. The content of the LEGO table in terms of Bionicle figures also facilitated both individual and social engagement. In the case of the Hydroscopes, we saw how, in one instance, a transformation from individual to social engagement involved a focus on the content of the installation, whereas in another instance, the transformation revolved around the physical qualities of Hydroscopes. In the case of Aarhus by Light, we saw how understanding territorial issues involved a combination of physical and social aspects of engagement.

Looking at the cultural elements, all three installations to various degrees broke with the conventions of the locations in which they were installed: At the department store, the children seemed comfortable breaking with the norm of not playing with the toys in the store, whereas one of the men in park of Musikhuset seemed slightly reluctant to reveal to others that he was exploring the installation. In terms of exhibitions, the Hydroscopes challenged the idea that a marine centre is usually a place where you observe fish and read about their characteristics. For some visitors, this transformation in mode, from primarily being observers to being creators, did meet with some reluctance. This was due not only to the design of the installations, but was also evidence of the way institutions embody particular forms of practice; people know what to expect when they go to museums (aquaria), or use public spaces. These expectations are, however, far from unambiguous or stable; in the world of museums, recent years have seen the development and use of various kinds of interactive technologies to support exhibition concepts in which visitors relate to exhibitions through the means of construction and active exploration. Similar developments may be observed in urban areas, where a range of interactive services has become commonplace. Through these developments, the norms and structures of the kinds of activities that are expected are gradually transformed.

Apart from providing insights into the dynamic nature of engagement, our cases also illustrate how engagement may evolve through relatively distinct transformations between the social, cultural, and physical elements. In many of our examples, these transformations were sparked by changing social conditions. In the case of the Hydroscopes, not only is the girl's engagement transformed from individual to social when her family enters the room, this transformation also meant that she re-engaged with the installations in a distinctly social mode. Where the Hydroscopes exemplified how these transformations may be relatively distinct, the LEGO Table and Aarhus by Light examples show how these transformations may be more fluid, as people's engagement fluctuates among physical, social, or content-related elements.

Taken together, our cases demonstrate how we may conceptualize engagement as evolving relationships between physical, social, cultural and content-oriented 
elements. Understanding the dynamics of engagement with any given interactive installation entails understanding how these elements are continuously re-shaped and formed into new constellations.

Acknowledgments. This research has been funded by the Danish Council for Strategic Research (Digital Urban Living, grant 09-063245).

\section{References}

1. Aarseth, E.: Nonlinearity and Literary Theory. In: Landow, G. (ed.) Hyper/Text/Theory. Johns Hopkins University Press, Baltimore (1994)

2. Benford, S., Giannachi, G., Koleva, B., Rodden, T.: From interaction to trajectories: designing coherent journeys through user experiences. In: Proceedings of CHI, pp. 709718. ACM, New York (2009)

3. Dalsgaard, P.: Designing for Inquisitive Use. In: Proceedings of DIS 2008, Penn State, Pensylvania (2008)

4. Dalsgaard, P., Dindler, C.: Peepholes as Means of Engagement in Interaction Design. In: Proceedings of Nordes 2009: the Third Nordic Design Research Conference, Oslo, Norway (2009)

5. Dalsgaard, P., Hansen, L.K.: Performing Perception - Staging Aesthetics of Interaction. ACM Transactions on Computer Human Interaction 15(3) (2008)

6. De Certeau, M.: The practice of everyday life. University of California Press, Berkeley (1984)

7. Dewey, J.: Art as Experience. Perigree, New York (1934)

8. Dourish, P.: Where the Action Is: The Foundations of Embodied Interaction. MIT Press, Cambridge (2001)

9. Dunne, A.: Hertzian tales: electronic products, aesthetic experience and critical design. Royal College of Art Research Resrach Publications, London (1999)

10. Edmonds, E., Muller, L., Connell, M.: On creative engagement. Journal of Visual Communication 5(3), 307-322 (2006)

11. Forlizzi, J., Battarbee, K.: Understanding experience in interactive systems. In: DIS 2004: Proceedings of the 5Th Conference On Designing Interactive Systems, pp. 261-268. ACM, New York (2004)

12. Fritsch, J.: Understanding affective engagement as a resource in interaction design. In: Proceedings of Nordes 2009: the Third Nordic Design Research Conference, Oslo, Norway (2009)

13. Garfinkel, H.: Studies in ethnomethodology. Polity Press, Cambridge (1967)

14. Gaver, W.W., Bowers, J., Boucher, A., Gellersen, H., Pennington, S., Schmidt, A., Steed, A., Villars, N., Walker, B.: The drift table: designing for ludic engagement. In: Proceedings of CHI 2004, pp. 885-900. ACM Press, New York (2004)

15. Gedenryd, H.: How Designers Work. Lund University Cognitive Studies, Sverige (1998)

16. Genette, G.: Narrative Discourse: An Essay in Method. Cornell University Press, Ithica (1983)

17. Grudin, J.: Groupware and social dynamics: eight challenges for developers. Communications of the ACM 37(1), 92-105 (1994)

18. Hedegaard, M.: Tænkning, Viden, Udvikling. Aarhus University Publishing, Aarhus (1995) 
19. Hindmarsh, J., Heath, C., vom Lehn, D., Cleverly, J.: Creating Assemblies: Aboard the Ghost Ship. In: Proceedings of CSCW, pp. 156-165. ACM, New Orleans (2002)

20. Hutchins, E.: Cognition in the wild. MIT Press, Cambridge (1995)

21. Kaltenbrunner, M., Bencina, R.: ReacTIVision: a computer-vision framework for tablebased tangible interaction. In: Proc. Tangible and Embedded Interaction (TEI 2007), pp. 69-74 (2007)

22. Klemmer, S.R., Hartman, B., Takayama, L.: How Bodies Matter: Five Themes for Interaction Design. In: Proceedings of DIS. ACM Press, New York (2006)

23. Manovich, L.: The Language of New Media. MIT Press, Cambridge (2001)

24. Massumi, B.: The Thinking-Feeling of What Happens. In: Massumi, B., Mertins, D., Spuybroek, L., Marres, M., Hubler, C. (eds.) Interact or Die: there is Drama in the Networks, pp. 70-91. NAI Publishers (2007)

25. Mogensen, P.: Towards a provotyping approach in system development. Scandinavian Journal of Information Systems 3, 31-53 (1992)

26. Nardi, B.A. (ed.): Context and consciousness: activity theory and human-computer interaction. MIT Press, Cambridge (1996)

27. Nielsen, R., Fritsch, J., Halskov, K., Brynskov, M.: Out of the Box - Exploring the Richness of Children's Use of an Interactive Table. In: IDC (2009)

28. O’Hara, K., Perry, M., Churchill, E., Russell, D.: Public and Situated Displays: Social and Interactional Aspects of Shared Display Technologies. Kluwer Academic, Dordrecht (2003)

29. Petersen, M.G., Iversen, O.S., Krogh, P.G., Ludvigsen, M.: Aesthetic interaction: a pragmatist's aesthetics of interactive systems. In: Proceedings DIS, pp. 269-276. ACM, New York (2004)

30. Rogers, Y.: Moving on from weiser's vision of calm computing: Engaging ubiComp experiences. In: Dourish, P., Friday, A. (eds.) UbiComp 2006. LNCS, vol. 4206, pp. 404421. Springer, Heidelberg (2006) 